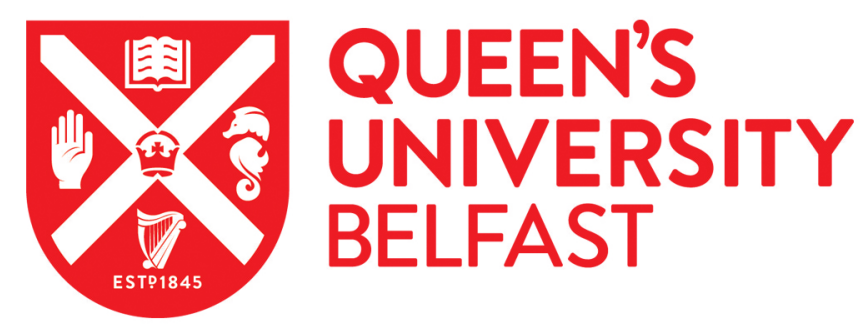

\title{
Photocatalyst activity indicating adhesive labels for use in the field
}

Mills, A., Hawthorne, D., Hazafy, D., \& Wells, N. (2018). Photocatalyst activity indicating adhesive labels for use in the field. Journal of Photochemistry and Photobiology A: Chemistry, 356, 256-262.

https://doi.org/10.1016/j.jphotochem.2018.01.005

Published in:

Journal of Photochemistry and Photobiology A: Chemistry

Document Version:

Peer reviewed version

Queen's University Belfast - Research Portal:

Link to publication record in Queen's University Belfast Research Portal

\section{Publisher rights}

Copyright 2018 Elsevier.

This manuscript is distributed under a Creative Commons Attribution-NonCommercial-NoDerivs License

(https://creativecommons.org/licenses/by-nc-nd/4.0/), which permits distribution and reproduction for non-commercial purposes, provided the author and source are cited.

\section{General rights}

Copyright for the publications made accessible via the Queen's University Belfast Research Portal is retained by the author(s) and / or other copyright owners and it is a condition of accessing these publications that users recognise and abide by the legal requirements associated with these rights.

Take down policy

The Research Portal is Queen's institutional repository that provides access to Queen's research output. Every effort has been made to ensure that content in the Research Portal does not infringe any person's rights, or applicable UK laws. If you discover content in the Research Portal that you believe breaches copyright or violates any law, please contact openaccess@qub.ac.uk. 


\title{
Photocatalyst activity indicating adhesive labels for use in the field
}

\author{
A. Mills*, D. Hawthorne, D. Hazafy and N. Wells \\ School of Chemistry and Chemical Engineering, Queens University Belfast, David Keir Building, \\ Stranmillis Road, Belfast, United Kingdom.
}

*(tel: +44(0)28 9097 4339, fax: +44(0)28 9097 6524, email: andrew.mills@qub.ac.uk)

\section{Abstract}

The preparation and characterisation of a resazurin-based photocatalyst activity indicator label is described. The label is applied to a number of different $\mathrm{TiO}_{2}$-based, photocatalytic materials, including self-cleaning: glass, tile, paint and awning materials, as well as a thin, sol-gel film, produced in-house. In all cases, the label exhibited a blue to pink colour transition upon irradiation with UV light. In most cases, the time taken to bleach $90 \%$ of the red component of the digital image of the ink, $t t b(90)$, was twice that for a traditional Rz ink, produced by the drawdown method, since the former was twice as thick. Although not as fast as a drawdown Rz ink, by a factor of ca two, it still only takes minutes to change and the Rz label is much more easily used, stored and does not need the sample to be: very smooth, horizontal or flat. As such it appears ideal for testing samples, both quantitatively and qualitatively in situ, i.e. in the field.

\section{Graphical Abstract}

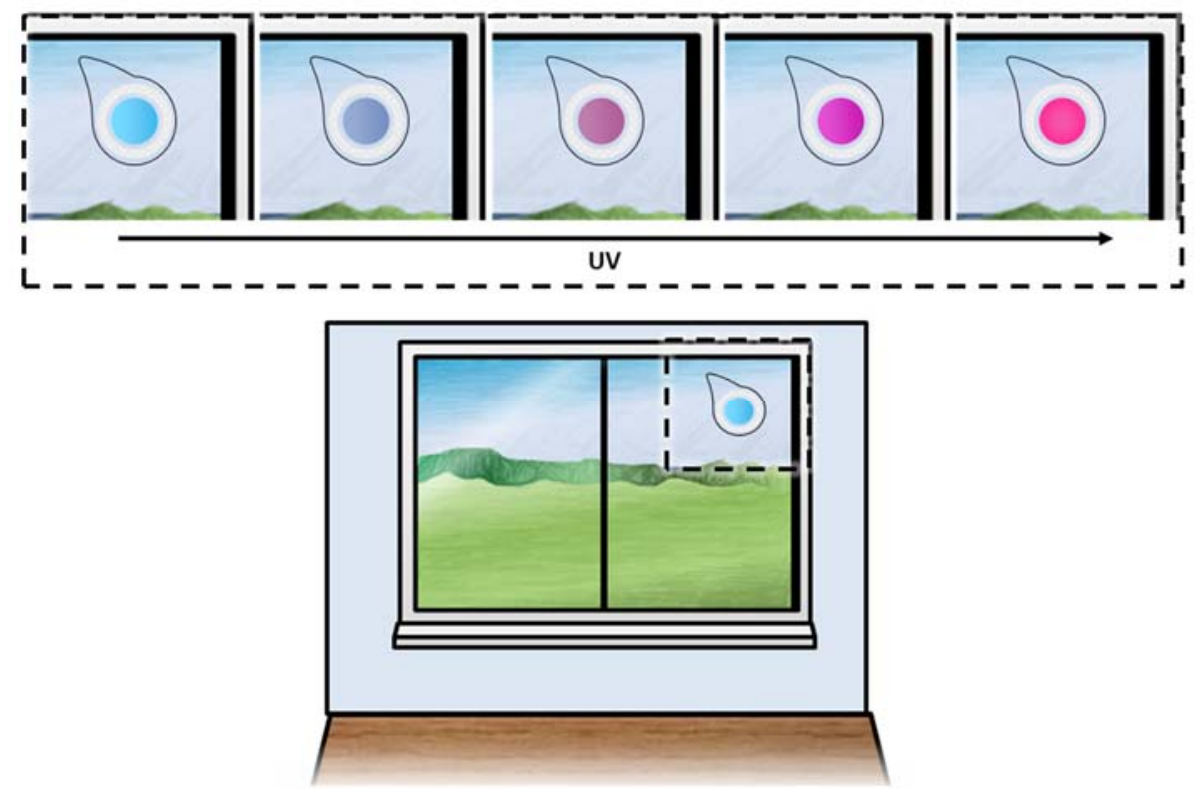

Key words: photo catalyst indicator, resazurin, label, indicator 


\subsection{Introduction}

Commercial photocatalytic self-cleaning materials are finding increasing usage throughout the world, with the market's total worth being projected at over $\$ 3$ billion for 2020 [1]; the bulk of this use is in the form of architectural materials, such as self-cleaning: glass, paint, awning and concrete materials $[2,3]$. It follows that there is a real need for novel, accessible and economical testing methods for assessing the efficacies of such materials. Both the manufacturers and end-users of such materials are beginning to eschew the more traditional, costly photocatalytic testing techniques (the methylene blue ISO test, for example [4,5]), which are often slow and require dedicated technical support, in favour of more rapid assessment techniques, such as photocatalyst activity indicator inks, i.e. paiis $[6,7]$.

A paii is an ink comprising a redox-indicating dye (usually the dye, resazurin, Rz), a sacrificial electron donor (SED), often glycerol, and a polymer binder, such as hydroxyethyl cellulose (HEC) [8]. The ink is used to coat a photocatalytic surface under test and, as such, may be applied using a felt-tipped pen $[9,10]$, aerosol spray [11] or ink draw-down $[8,12]$. In the case of an Rz paii, the generation of surface electron/hole pairs by the photocatalytic material under test, when irradiated by light of sufficiently high energy ( $h v \geq E_{b g}$ ), results in the subsequent rapid oxidation of the SED and the concomitant reduction of the $\mathrm{Rz}$ (blue) to resorufin, $\mathrm{Rf}$ (pink) in the paii $[8,10]$. Paiis of this, and other, closely related, formulations have been adopted widely in recent years as the primary testing technique in many research articles detailing the development of new photocatalysts, as well as in industry. Examples of the growing use of paiis are given in Error! Not a valid bookmark selfreference.. 
Table 1: Examples of paiis used as an assessment technique for a variety of photocatalytic surfaces [10-27]

\begin{tabular}{|c|c|c|}
\hline Ref & Paii(s) used & Materials tested / comments \\
\hline$[10]$ & $\mathrm{Rz} / \mathrm{HEC}$ & $\begin{array}{c}\text { Activ }^{\mathrm{TM}} ; \mathrm{CVD}^{\mathrm{b}} \mathrm{TiO}_{2} \text { films; first use of pen as an } \\
\text { application method }\end{array}$ \\
\hline$[11]$ & Rz/HEC & $\begin{array}{l}\text { CVD } \mathrm{TiO}_{2} \text { films; first use of aerosol spray as } \\
\text { application method }\end{array}$ \\
\hline$[12]$ & $\begin{array}{l}\text { Rz/HEC; BB66/HEC, } \\
\text { AV7/HEC }^{a}\end{array}$ & $\begin{array}{l}\text { BioClean®; Deutshce-Steinzeug tiles; StoColor } \\
\text { Climasan paint; paiis formulated with different } \\
\text { dyes to suit the assessment of markedly different } \\
\text { surfaces and activities }\end{array}$ \\
\hline$[13]$ & Rz/HEC & $\begin{array}{l}\mathrm{TiO}_{2} \text { films with varying porosity and loading; Rz } \\
\text { ink dip-coated onto films cast onto glass. }\end{array}$ \\
\hline$[14]$ & Rz/HEC & C-doped sputter-formed $\mathrm{TiO}_{2}$ films \\
\hline [15] & Rz/HEC & Coloured Zn/borophosphate glasses \\
\hline$[16]$ & Rz/HEC & $\mathrm{N}$-doped $\mathrm{CVD} \mathrm{TiO}_{2}$ films \\
\hline$[17]$ & $\mathrm{Rz} / \mathrm{HEC}$ & $\begin{array}{c}\text { Aerosol-assisted CVD } \mathrm{TiO}_{2} \text { films influenced by } \\
\text { electric fields }\end{array}$ \\
\hline [18] & Rz/HEC & $\mathrm{PbO}$-modified $\mathrm{TiO}_{2}$ films \\
\hline [19] & Rz/HEC & CVD $\mathrm{TiO}_{2}$ films \\
\hline$[20]$ & Rz/HEC & Films of $\mathrm{y}-\mathrm{Bi}_{2} \mathrm{MoO}_{6}$ \\
\hline [21] & Rz/HEC & $\begin{array}{l}\text { N-doped CVD } \mathrm{TiO}_{2} \text { films; } \text { Activ }^{\mathrm{TM}} \text {; Rate data } \\
\text { generated from RGB rather than Abs }\end{array}$ \\
\hline$[22]$ & Rz/HEC & $\mathrm{TiO}_{2}$ sol-gel modified with surfactant \\
\hline$[23]$ & Rz/HEC & Rutile and anatase $\mathrm{TiO}_{2}$ surfaces \\
\hline [24] & Rz/HEC & Photocatalytic cements \\
\hline$[25]$ & Rz/HEC & Fe(III)-substituted hydroxyapatite photocatalyst \\
\hline$[26]$ & $\mathrm{Rz} / \mathrm{HEC}$ & $\begin{array}{l}\mathrm{TiO}_{2} \text { films doped with various dopants and coated } \\
\text { on various substrates }\end{array}$ \\
\hline$[27]$ & Rz/HEC & Photocatalytic cements; Rz paii used in industry \\
\hline
\end{tabular}


Of all the techniques used to apply the ink, the drawdown method, using a K-bar, is the most popular, since it delivers a highly reproducible film on a smooth surface, yielding a wet ink film, thickness ca. $24 \mu \mathrm{m}$, which then dries within 10-15 min to form a film ca. $2.1 \mu \mathrm{m}$ thick [28].

Figure 1(a) illustrates the results of a typical experiment in which an Rz paii has been coated using a K-Bar (No. 3) onto a photocatalyst glass surface and irradiated with UVA light, whilst its UV-vis spectrum is monitored as a function of irradiation time.

(a)

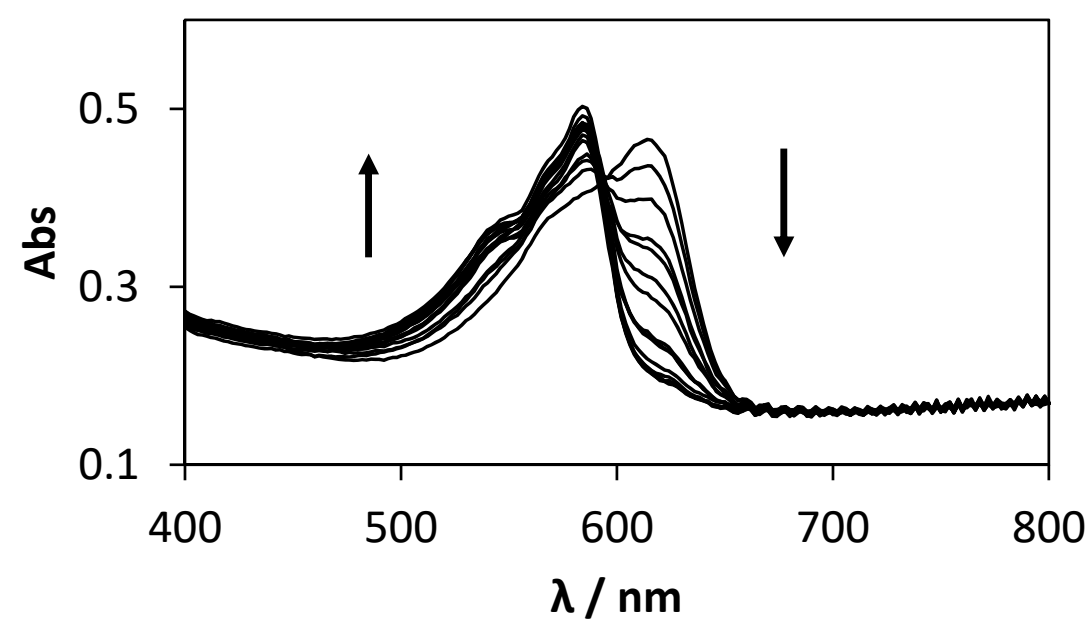

(b)
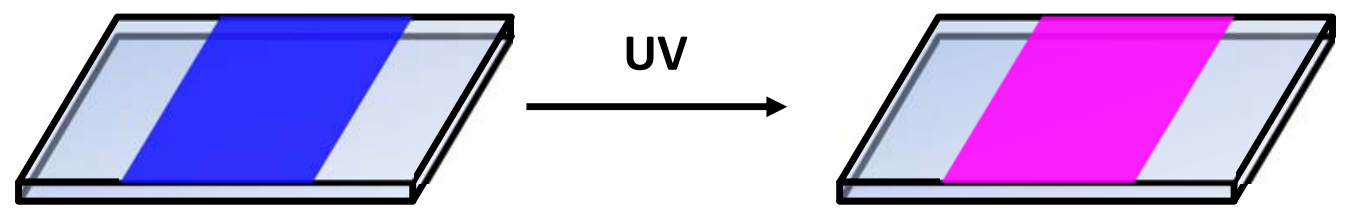

Figure 1: (a) UV-vis absorption spectra for a typical, K-bar coated paii film on a sheet of photocatalytic, selfcleaning glass, recorded as a function of UV irradiation time (i.e. every $30 \mathrm{~s}$ for $7 \mathrm{~min}$ using a blacklight, BL, lamp, $\left.\lambda_{\max }=352 \mathrm{~nm}(\mathrm{FWHM}=40 \mathrm{~nm}) ; 2.0 \mathrm{~mW} \mathrm{~cm}{ }^{-2}\right)$; (b) schematic of the observed change in colour of the paii coated onto a photocatalytic ally active film, upon UV irradiation.

These results show that the photocatalytic film under test is able to mediate the rapid reduction of $\mathrm{Rz}$ to Rf by UV light, i.e.

$$
\mathrm{Rz}+\text { glycerol } \underset{h v \geq \mathrm{E}_{\mathrm{bg}}}{\mathrm{SC}} \mathrm{Rf}+\text { glyceraldehyde }
$$

Where $\mathrm{SC}=$ semiconductor photocatalyst, usually $\mathrm{TiO}_{2}$. However, this popular K-bar ink drawdown technique is not without its limitations. For example, it requires the photocatalyst surface to be largely horizontal, i.e. it is not really suitable for testing vertical or steeply inclined samples, as might be found when testing surfaces in-situ. Similarly, the photocatalytic film should also, ideally, be flat, since the more curved the surface, the greater the difficulty in producing a uniform ink film. In addition, some 
practice is required in order to be able to generate routinely a uniform ink film using the draw-down technique. The photocatalytic film must be smooth, since any surface roughness of the material under test that is greater than ca. $24 \mu \mathrm{m}$ [28], vide supra, this will tend to produce a non-uniform, i.e. patchy, ink film. Finally, carrying the ink and a K-bar around for testing samples in the field is not particularly convenient.

As a consequence, there exists a need for a more easily applied, non-invasive and cost-effective delivery method for the paii technology for use on a wide range of photocatalytic materials that are not necessarily horizontal, flat or very smooth and such a test would find particular use in the field. Thus, in this paper, we describe the production of an Rz-based paii label, produced by a screen printing process. The response of this label is tested using a range of commercially-available, photocatalytic surfaces of different types including photocatalytic glass, paint, and tile. 


\subsection{Experimental}

\subsection{Chemicals and materials}

All materials were purchased at the maximum available purity grade from Sigma-Aldrich, unless stated otherwise. The pressure-sensitive adhesive polymer used to make the label was Tackwhite AT 4M1, from IChemCo. A list of the $\mathrm{TiO}_{2}$-based photocatalytic test materials used in this work, and their features, are listed in Table 2.

Table 2: Photocatalytic test materials

\begin{tabular}{|c|c|c|c|c|}
\hline Name & Manufacturer & Material features & Photocatalyst & $\begin{array}{c}\text { Average } \\
\text { surface } \\
\text { roughness / } \\
\mathrm{nm}^{\mathbf{b}}\end{array}$ \\
\hline $\operatorname{Activ}^{\mathrm{TM}}$ & Pilkington [29] & Glass, $4 \mathrm{~mm}$ thickness & $\begin{array}{c}\mathrm{TiO}_{2}, 15 \mathrm{~nm} \text { thick } \\
{[30]}\end{array}$ & 34 \\
\hline BioClean® & $\begin{array}{c}\text { Saint-Gobain Glass } \\
{[31]}\end{array}$ & Glass, $4 \mathrm{~mm}$ thickness & $\begin{array}{c}\mathrm{TiO}_{2}, 15 \mathrm{~nm} \\
\text { thickness }+2 \mathrm{~nm} \\
\text { Al-doped } \mathrm{SiO}_{2} \\
(8 \%)[30]\end{array}$ & 13 \\
\hline $\begin{array}{l}\text { Sheerfill }{ }^{\circledR} \text { V } \\
\text { with } \\
\text { Everclean } ®\end{array}$ & Saint-Gobain [32] & $\begin{array}{c}\text { Poly(tetrafluoroethylene), } \\
0.5 \mathrm{~mm} \text { thickness }\end{array}$ & $\begin{array}{l}\mathrm{TiO}_{2}, 1.5 \mu \mathrm{m} \\
\text { thickness, ca. } \\
25 \% \text { surface } \\
\text { coverage [33] }\end{array}$ & - \\
\hline $\begin{array}{l}\text { StoColor } \\
\text { Climasan }\end{array}$ & Sto [34] & Silicate-based paint & $\begin{array}{c}\mathrm{TiO}_{2}, 10 \% \text { wt. } \\
\text { loading in paint } \\
\text { [35] }\end{array}$ & 338 \\
\hline Hydrotect & $\begin{array}{c}\text { Deutsche-Steinzeug } \\
{[36]}\end{array}$ & Ceramic tile & $\begin{array}{l}\mathrm{TiO}_{2}, 0.1 \mu \mathrm{m} \\
\text { thickness [37] }\end{array}$ & 59 \\
\hline Sol-gel & $\begin{array}{l}\text { Produced in } \\
\text { laboratory }\end{array}$ & $\begin{array}{c}\text { Coated glass slide of } 1 \\
\text { mm thickness }\end{array}$ & $\begin{array}{l}\mathrm{TiO}_{2} \text {, ca. } 250 \mathrm{~nm} \\
\text { thick }\end{array}$ & 111 \\
\hline
\end{tabular}

a: Sol gel films prepared as described elsewhere [38], then diluted to 1 wt.\% concentration in $0.1 \mathrm{M} \mathrm{HNO}_{3}$, so that they can be coated (using a doctor blade technique) to yield an appropriately thin (250 $\mathrm{nm}$ ) film, but with ca. 5-15 $\mathrm{nm}$ particles [39] as measured by SEM (

Figure 2c).

b: Average roughness determined using AFM. The roughness of the Sheerfill $V$ awning's photocatalyst coating could not be determined, as the bulk material is itself rough on a macroscopic scale.

The surfaces of the materials were probed using a scanning electron microscope (FEI Quanta FEG Environmental SEM Oxford Ex-ACT) and the results of this work are illustrated in 
Figure 2. In all cases, the EDX facility on the SEM revealed a surface covered with $\mathrm{TiO}_{2}$. Studies investigating the morphology of each surface, conducted using AFM (a Nanosurf Flex-Axiom in dynamic force mode), showed that the surfaces exhibited a range of roughness, of which the two glass samples were the smoothest, and the Sto paint sample the roughest, see table 2.
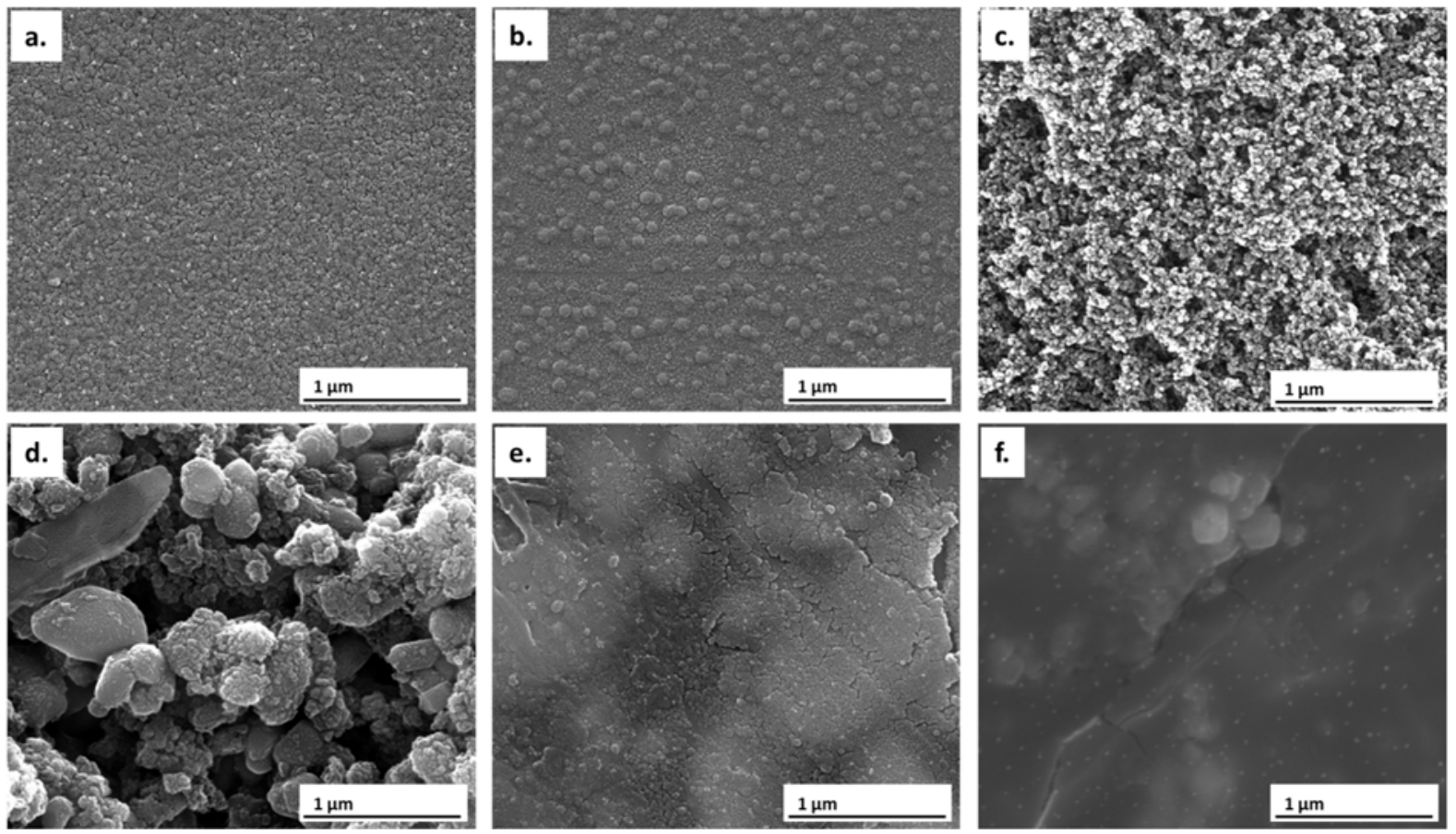

Figure 2: SEM Images of (a) Activ ${ }^{\mathrm{TM}}$ glass, (b.) BioClean® glass, (c) a $\mathrm{TiO}_{2}$ sol-gel film, (d) StoColor Climasan silicate-based paint (e) Hydrotect ceramic tile and (f) photocatalytic awning material all at 100,000 magnification (the space bar in all the images is for $1 \mu \mathrm{m}$ ).

The SEM's of the two samples of self- cleaning glass (Activ ${ }^{\top M}$ and BioClean $®$ ), i.e. figures 2(a) and (b), respectively, showed the particles were ca. $20 \mathrm{~nm}$ in diameter, although the BioClean also had larger floret-like, growths distributed across its surface, measuring ca. $95 \pm 10 \mathrm{~nm}$. Lab-based, cast sol-gel paste films, figure 2(c), comprised ca.10 nm particles, consistent with previously reported work of thicker films of the same sol-gel material [38]. StoColor Climasan silicate-based paint film, figure 2(d), hadTiO 2 particles with apparent particle size of ca. $50 \pm 6 \mathrm{~nm}$. The ceramic tiles, figure 2(e), had $\mathrm{TiO}_{2}$ particles of ca. $68 \pm 8 \mathrm{~nm}$ distributed across the surface, which, in turn, appeared to be fused aggregates of smaller sized particles, ca. $30 \pm 5 \mathrm{~nm}$. The awning material, figure 2(f), was too fragile to be analysed using high-vacuum electron microscopy without being destroyed, however analysis using low vacuum SEM at the same magnification revealed an apparent $\mathrm{TiO}_{2}$ aggregate particle size of $230 \pm 20 \mathrm{~nm}$. The above photocatalytic materials provide a reasonably diverse range of surfaces and activities with which to test the $\mathrm{Rz}$ labels. 


\subsection{Formulation of a typical Rz draw-down ink}

A typical Rz ink was made by first adding $0.15 \mathrm{~g}$ of the water-soluble cellulose ether, hydroxyethyl cellulose (HEC; average $\mathrm{MW}=320 \mathrm{k} \mathrm{g} \mathrm{mol}^{-1}$ ) to $9.85 \mathrm{~g}$ of water, to give a polymer concentration of 1.5 wt \%. To this were added $1 \mathrm{~g}$ glycerol and $10 \mathrm{mg} \mathrm{Rz}$ ( $\mathrm{Na}$ salt) and the resulting ink was then stirred overnight on a magnetic stirrer plate to ensure all the components were fully dissolved.

\subsection{Formulation of the screen-printable $R z$ ink}

A typical screen-printable paii was produced by dissolving $3.5 \mathrm{~g}$ of the alcohol-soluble, cellulose ether, hydroxypropyl cellulose (HPC; average $\mathrm{MW}=80 \mathrm{k} \mathrm{g} \mathrm{mol}^{-1}$ ) in a binary solvent solution, comprising: 62 $\mathrm{g} n$-butanol and $6.2 \mathrm{~g}$ ethanol, to give a polymer concentration of $5 \mathrm{wt} \%$. To this were added $4 \mathrm{~g}$ of the sacrificial electron donor, glycerol, and $200 \mathrm{mg}$ of the redox-active dye, Rz (Na salt). The ink was then allowed to stir overnight to ensure the complete dissolution and mixing of the ink components. Unlike the water-based ink reported in section 2.2 (viscosity = ca. $980 \mathrm{mPa} \mathrm{s}$ ), this solvent-based Rz ink had a suitably low viscosity (ca. $105 \mathrm{mPa}$ ) for screen printing.

\subsection{Screen printing an adhesive paii label}

In screen printing, ink deposition is achieved by forcing the ink through a negative template (formed from permeable portions of an otherwise impermeable screen), onto a substrate which is placed beneath the screen, using a squeegeeing action. In this work a model SD-05 screen printer (RokuPrint) was used to print both the solvent-based $\mathrm{Rz}$ ink and the adhesive, using appropriate different bespoke designed silk screen templates, made and supplied by GK Marketing Supplies Ltd. Thus, the solvent-based paii was printed through a 43 thread $\mathrm{cm}^{-1}$ mesh screen, with an inkpermeable small disc-shape design (diameter $=1.7 \mathrm{~cm}$ ) onto a sheet of polyethylene terephthalate (PET; $50 \mu \mathrm{m}$ thickness), using a squeegee velocity of ca. $23 \mathrm{~cm} \mathrm{~s}^{-1}$. The final dry disc ink film produced was approximately $4 \mu \mathrm{m}$ thick. This was then followed by the printing of a ring layer of the pressure sensitive adhesive, i.e. PSA, (with: inner diameter $=2.25 \mathrm{~cm}$ and outer diameter $=3.0 \mathrm{~cm}$, so that the thickness of the adhesive band was $3.75 \mathrm{~mm}$, around the paii disc on the PET film. This second screen printing step used a differently designed, bespoke mesh screen, under otherwise identical printing parameters. A gap of $0.275 \mathrm{~cm}$ was maintained at all points between the central paii 'disc' layer and the surrounding PSA ring. In order to achieve this reproducibly, a screen with a slightly higher thread density $\left(77\right.$ thread $\left.\mathrm{cm}^{-1}\right)$ was chosen for the screen printing of the PSA (viscosity $=600 \mathrm{mPa} \mathrm{s}$ ), since higher thread counts improve print definition [40]. The dry film thickness of the printed adhesive was ca. $10 \mu \mathrm{m}$.

The screen-printed adhesive and paii were allowed to dry in air in the dark for $48 \mathrm{~h}$ before being applied to a protective layer comprising: a cellulose acetate (CA) projection sheet (100 micron thickness, Hartwii), which was then laminated with PET $(2 \times 80$ micron sheet laminator pouches, provided by Swordfish); this protective layer prevented any further drying out of the indicator film during storage. The CA sheet in the protective layer usually had black ink printed on its surface so as to protect the underlying $\mathrm{Rz}$ paii from photobleaching due to ambient light. Whilst the Rz ink/adhesive on PET film was cut into $3 \mathrm{~cm}$ circles, the CA/PET protected sheet was cut into a slightly larger, tearshaped pattern so as to allow for its easy removal from the indicator layer when it came to peeling 
them apart. In later work, using bigger screens, it was possible to print 18 identical labels simultaneously, using the above technique, which could then be cut into individual units using a custom-designed die cutting template. Figure 3 shows a digital image and a schematic illustration of a typical label, although, in this case, the CA sheet was not printed with black ink, so as to render the underlying $\mathrm{Rz}$ paii visible.
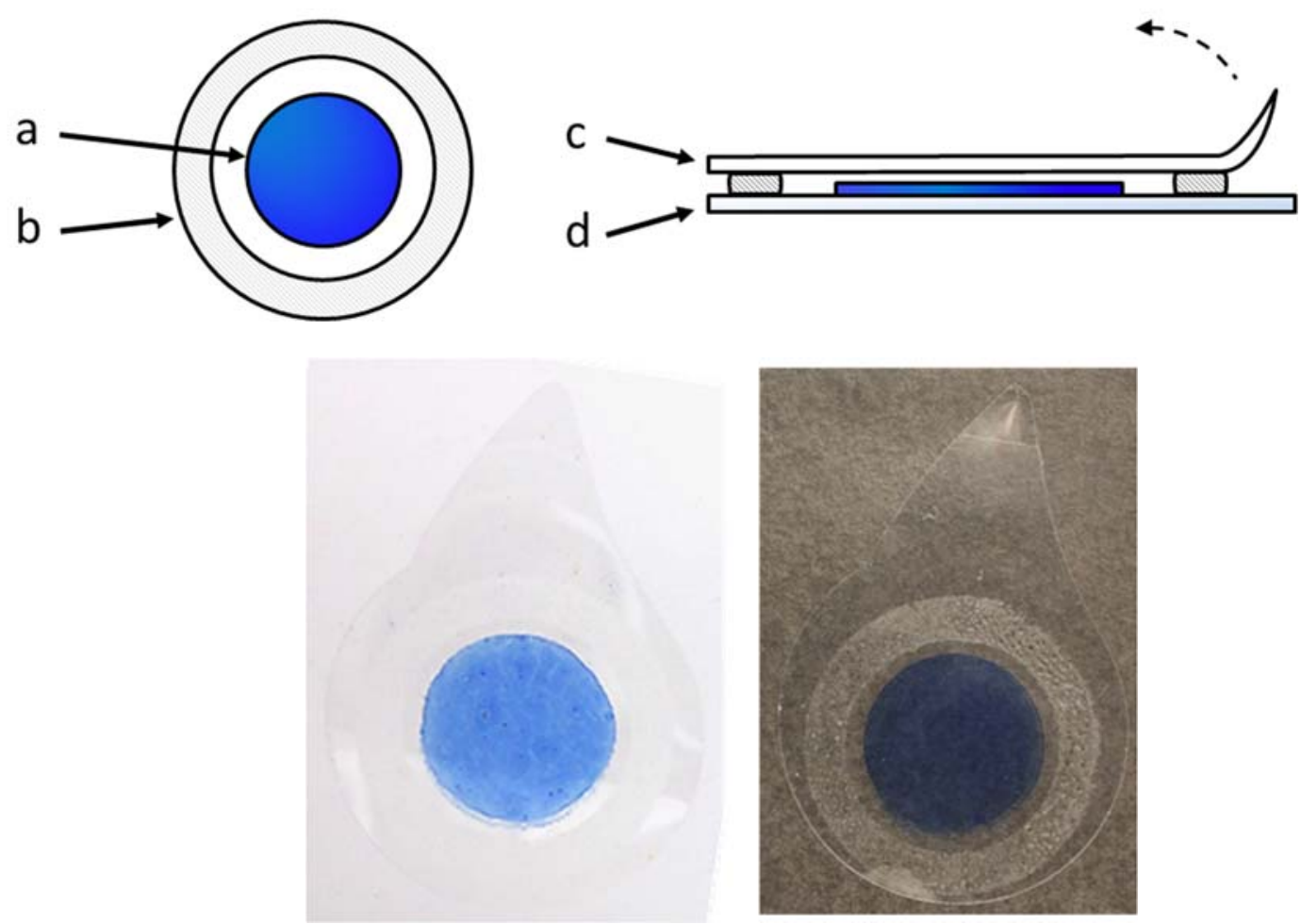

Figure 3: Top and side-views of the label, showing (a) the Rz paii circle $(17 \mathrm{~mm}$ diameter, $4 \mu \mathrm{m}$ dry film thickness), (b) the PSA ring band (3.75 mm band thickness, $10 \mu \mathrm{m}$ dry film thickness), (c) the protective, removable PET-laminated CA transparency cover (ca. $260 \mu \mathrm{m}$ dry thickness; 2 x $80 \mu \mathrm{m}$ laminate sheets that make up the laminating pouch, plus $1 \times 100 \mu \mathrm{m}$ CA transparency sheet in between), (d) the underlying PET inkprinted substrate layer (ca. $50 \mu \mathrm{m}$ dry thickness). Lower: Digital images of the label on a white background to emphasise the blue paii, and on a grey background to emphasise the translucent PSA layer.

Note: since the irradiation of the semiconductor photocatalyst is usually carried out through the label (an obvious necessity for opaque samples) it follows that the dye (Rz), and its pink reduced form (Rf), and the ink's supporting substrate (50 $\mu \mathrm{m}$ PET here) must not absorb strongly this radiation. Fortunately, both Rz and Rf absorb little UVA (315 - $400 \mathrm{~nm}$ ) [28] and the same is true for the PET film, which, for example, had an absorbance of ca. 0.05 at $352 \mathrm{~nm}$, i.e. the maxima of the UVA BL used in this work.

\subsection{Assessment of photocatalytic surface activity using the label and ink}

For the purposes of this work, unless otherwise stated, all irradiations were carried out using a $15 \mathrm{~W}$ black light lamp (Eiko), with an emission peak maximum, $\lambda_{e m}$, at $352 \mathrm{~nm}(\mathrm{FWHM}=40 \mathrm{~nm}$ ), and an 
irradiance of $2.0 \mathrm{~mW} \mathrm{~cm}^{-2}$. All photocatalytic test samples were pre-treated under the same UV irradiation conditions for $1 \mathrm{~h}$ prior to testing, so as to clean the surface photocatalytically by mineralising any organic pollutants that may be on the surface of the sample under test, and also to render the surface superhydrophilic, so as to improve the adhesion of the screen-printed label when applied subsequently.

Once the sample under test was cleaned using UV light, a screen-printed label was peeled from its PET/CA protecting top-cover film and stuck to the surface carefully, so as to avoid trapping any air bubbles. The label was then smoothed, by thumb or cylindrical roller, to remove any remaining trapped air and enhance its contact with the underlying sample. The label-covered sample was then irradiated with UV light, as described above, and its colour monitored regularly using digital photography. The images of the label were analysed using RGB colour analysis, via the software package ImageJ [41], which then allowed the average values of the red, RGB(red), blue, RGB(blue), and green, $\mathrm{RGB}$ (green) components of the image, to be extracted for each image, i.e. each image sampled at time, $t$. This in turn allowed the normalised value of the $R G B(r e d)$, i.e. $R_{t}$ to be calculated, via the expression:

$$
\mathrm{R}_{t}=\frac{\mathrm{RGB}(\text { red })_{t}}{\mathrm{RGB}(\text { red })_{t}+\mathrm{RGB}(\text { green })_{t}+\mathrm{RGB}(\text { blue })_{t}}
$$

The normalised red component was chosen since it gave the biggest change in value, as the Rz was photoreduced to Rf. Thus, from the photographic images of the change in colour of the Rz label recorded for each sample tested, a plot of $\mathrm{R}_{\mathrm{t}} \mathrm{vs}$ irradiation time, $t$, was generated; a typical example of which, for the label on Activ ${ }^{\mathrm{TM}}$ self-cleaning glass, is given in Figure 4, vide infra. Further details regarding this method of colour analysis are given elsewhere, [42,43]. The camera used in all this work was a Canon EOS 7D.

\subsection{Results \& Discussion}

\subsection{Rz label vs. a traditional Rz paii ink}

All initial tests on the label's response were carried out on Plkington Activ ${ }^{\mathrm{TM}}$ photocatalytic glass, as it is a well-studied material that has served as a commercial benchmark photocatalytic surface in many other studies, including ones using paiis $[12,44,45]$. In a typical experiment, the Rz label on Activ ${ }^{\mathrm{TM}}$ was irradiated with UV light and photographed as a function of irradiation time. These images and the results of the RGB analysis, i.e. a plot of $\mathrm{R}_{\mathrm{t}} \mathrm{vs}$. $t$, are illustrated in Figure $\mathbf{4}$ and reveal a value for $t t b(90)$ (i.e. the time taken to reach $90 \%$ of the maximum value of $R_{t}$ ) of 8.8 min (highlighted in by a red dot in Figure 4). The same sample of self-cleaning glass was also tested, under the same conditions, using the traditional drawdown Rz ink, which was monitored and analysed in the same manner as the $\mathrm{Rz}$ label so as to yield an $\mathrm{R}_{\mathrm{t}} \mathrm{vs}$. $t$ plot that that was noticeably sharper in response to that shown by the Rz label, with a $t t b(90)$ of 3.8 min [12]. The drawdown Rz ink (2.1 $\mu \mathrm{m}$ thick) 
obviously responds much faster (by about a factor of two) than the screen-printed label ( $4 \mu \mathrm{m}$ thick), which is not surprising, given the kinetics of Rz reduction have been found to be inversely dependent upon film thickness [28].
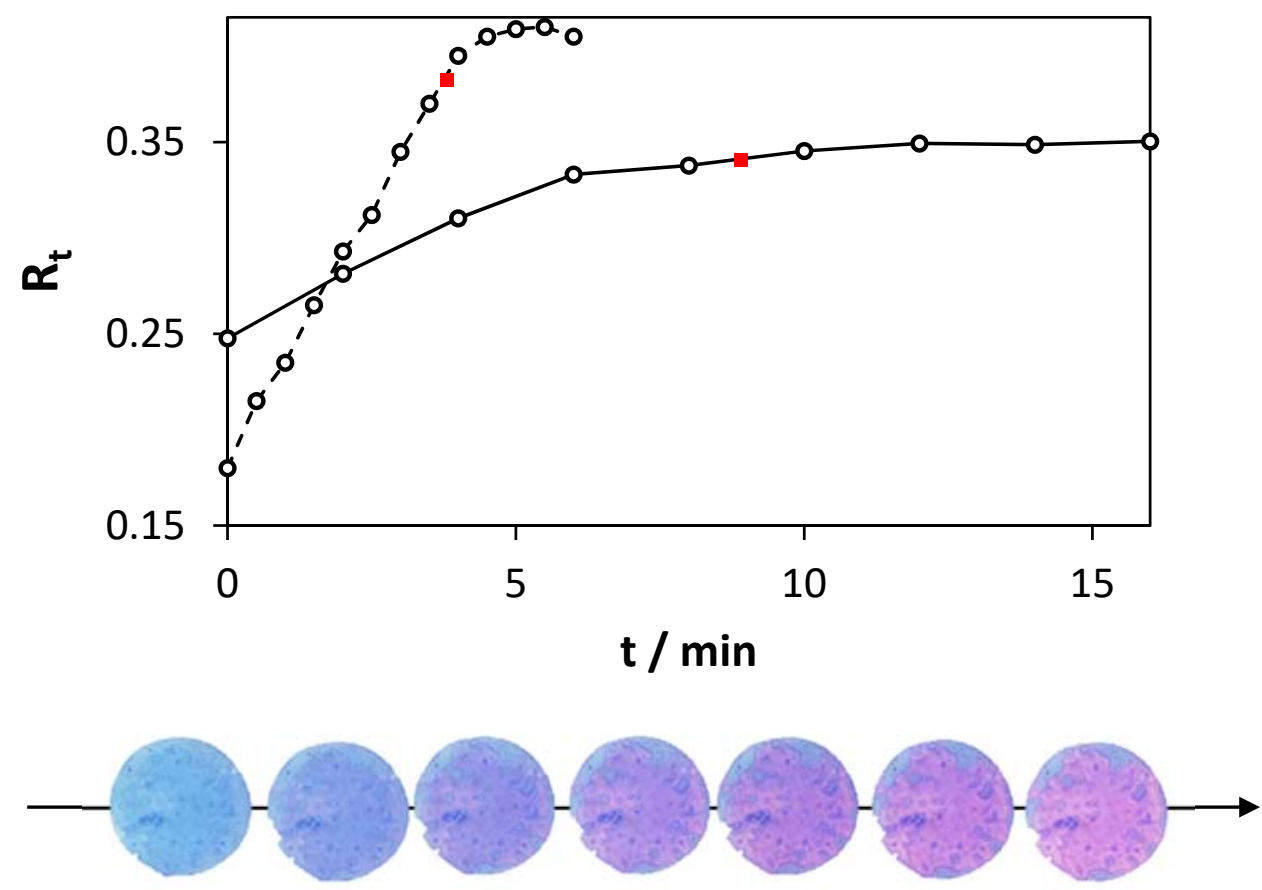

Figure 4: Photographs and accompanying normalised $\mathrm{R}_{\mathrm{t}}$ data recorded of a $\mathrm{Rz}$ paii label affixed to a sheet of Activ $^{\mathrm{TM}}$ glass and irradiated using two $15 \mathrm{~W}$ BL lamps with $\lambda_{\mathrm{ex}}=352 \mathrm{~nm}(\mathrm{FWHM}=40 \mathrm{~nm}), 2.0 \mathrm{~mW} \mathrm{~cm}^{-2}$ for 15 $\min$ (solid line) and of a Rz paii ink under the same conditions for 6 min (broken line). The red dots signify $t$ tb(90) values of $3.8 \mathrm{~min}$ for the ink, and $8.8 \mathrm{~min}$ for the label.

A repeatability test carried out using five $\mathrm{Rz}$ labels produced on the same day, yielded an average $t t b(90)$ value of $8.8 \pm 0.16 \mathrm{~min}$, i.e. ca. $1.8 \%$, which compares well with that reported previously for the $\mathrm{Rz}$ ink test $( \pm 4.3 \% \%[46])$. Other work showed that the Rz label remained unchanged in colour and responsivity when stored in the dark, under otherwise ambient conditions for over 6 months.

\subsection{Assessment of photocatalytic surface activities}

The screen-printed Rz label was tested on a number of different commercial photocatalytic samples, the details of which are given in Commercial photocatalytic self-cleaning materials are finding increasing usage throughout the world, with the market's total worth being projected at over $\$ 3$ billion for 2020 [1]; the bulk of this use is in the form of architectural materials, such as self-cleaning: glass, paint, awning and concrete materials [2,3]. It follows that there is a real need for novel, accessible and economical testing methods for assessing the efficacies of such materials. Both the manufacturers and end-users of such materials are beginning to eschew the more traditional, costly photocatalytic testing techniques (the methylene blue ISO test, for example [4,5]), which are often slow and require dedicated technical support, in favour of more rapid assessment techniques, such as photocatalyst activity indicator inks, i.e. paiis $[6,7]$. 
A paii is an ink comprising a redox-indicating dye (usually the dye, resazurin, Rz), a sacrificial electron donor (SED), often glycerol, and a polymer binder, such as hydroxyethyl cellulose (HEC) [8]. The ink is used to coat a photocatalytic surface under test and, as such, may be applied using a felt-tipped pen $[9,10]$, aerosol spray [11] or ink draw-down $[8,12]$. In the case of an Rz paii, the generation of surface electron/hole pairs by the photocatalytic material under test, when irradiated by light of sufficiently high energy ( $h v \geq E_{b g}$ ), results in the subsequent rapid oxidation of the SED and the concomitant reduction of the $\mathrm{Rz}$ (blue) to resorufin, $\mathrm{Rf}$ (pink) in the paii $[8,10]$. Paiis of this, and other, closely related, formulations have been adopted widely in recent years as the primary testing technique in many research articles detailing the development of new photocatalysts, as well as in industry. Examples of the growing use of paiis are given in Error! Not a valid bookmark selfreference.. 
Table 1. Unless stated otherwise, all irradiations were carried out using the BL lamps and irradiance reported in Figure 4. Some of these digital photographic images generated as a result of this work are shown in Figure 5.

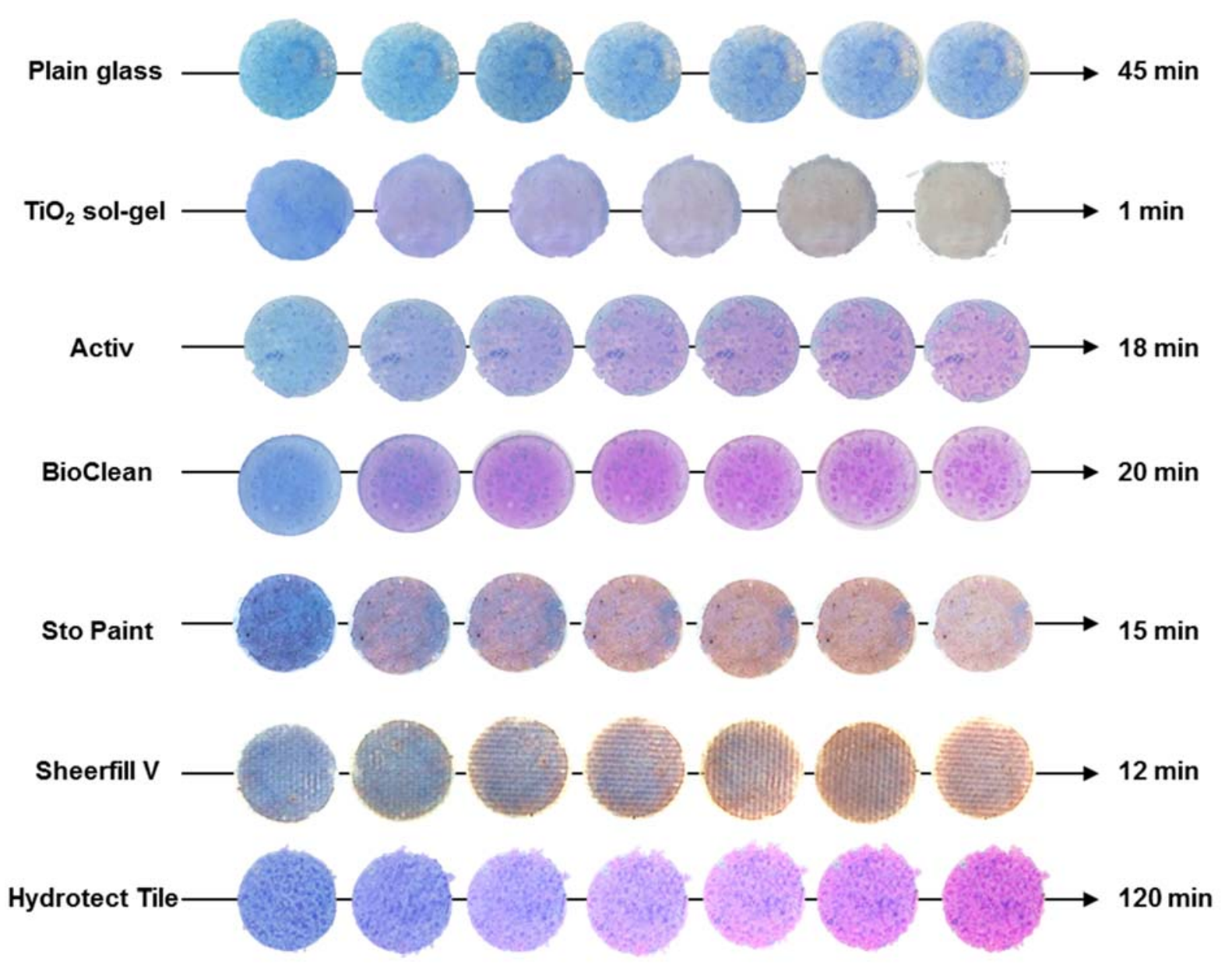

Figure 5: Digital photographic images, recorded of the Rz labels on a variety of different photocatalytic materials as a function of irradiation time. Note: in all cases the UV irradiance was $2.0 \mathrm{~mW} \mathrm{~cm}^{-2}$, except for the sol-gel film, for which it was $0.5 \mathrm{~mW} \mathrm{~cm}^{-2}$.

The photographic images generated in this study allowed the construction of a $\mathrm{R}_{\mathrm{t}} \mathrm{vs}$. $t$, plot, and determination of the $t t b(90)$ value, for each of the different photocatalytic materials tested; an example of which, generated using a typical Rz label applied to a sample of the photocatalytic awning material and irradiated under the usual conditions for $24 \mathrm{~min}$, is shown in Figure 6Figure 6.

The $t t b(90)$ data (generated from the Rt vs $t$ plots for each material shown in Figure 5) are collected in Table 3, along with $t t b(90)$ values reported previously for these same materials, or determined here, using the $\mathrm{Rz}$ ink test. The apparent order of photocatalytic activity (which is inversely proportional to the $t \mathrm{tb}(90)$ value [46]), is, for both the $\mathrm{RZ}$ label and ink,: $\mathrm{TiO}_{2}$ sol-gel > awning/tent material > paint > glass > tile. It is worthwhile noticing that, for many of the samples, the formation of the reduced pink form of Rz, i.e. Rf, is transitory, and that further irradiation causes this colour to fade. The latter feature is due to the further photocatalytic reduction of $\mathrm{Rf}$ to dihydroresorufin, which is 
colourless. The various observed colour transitions are slightly complicated by the fact that the samples of photocatalytic paint, awning and tile used here were all beige coloured to different extents, i.e. not perfectly white or colourless. However, for each of these samples, this background colour did not inhibit at all the creation of the necessary $R_{\mathrm{t}} \mathrm{vs}$. $t$, plot, and determination of the associated $t \operatorname{tb}(90)$ value, as illustrated by the $R_{t}$ vs. $t$, profiles in Figures 3 and 6 for Activ $^{\mathrm{TM}}$ and the commercial photocatalytic awning material, respectively.

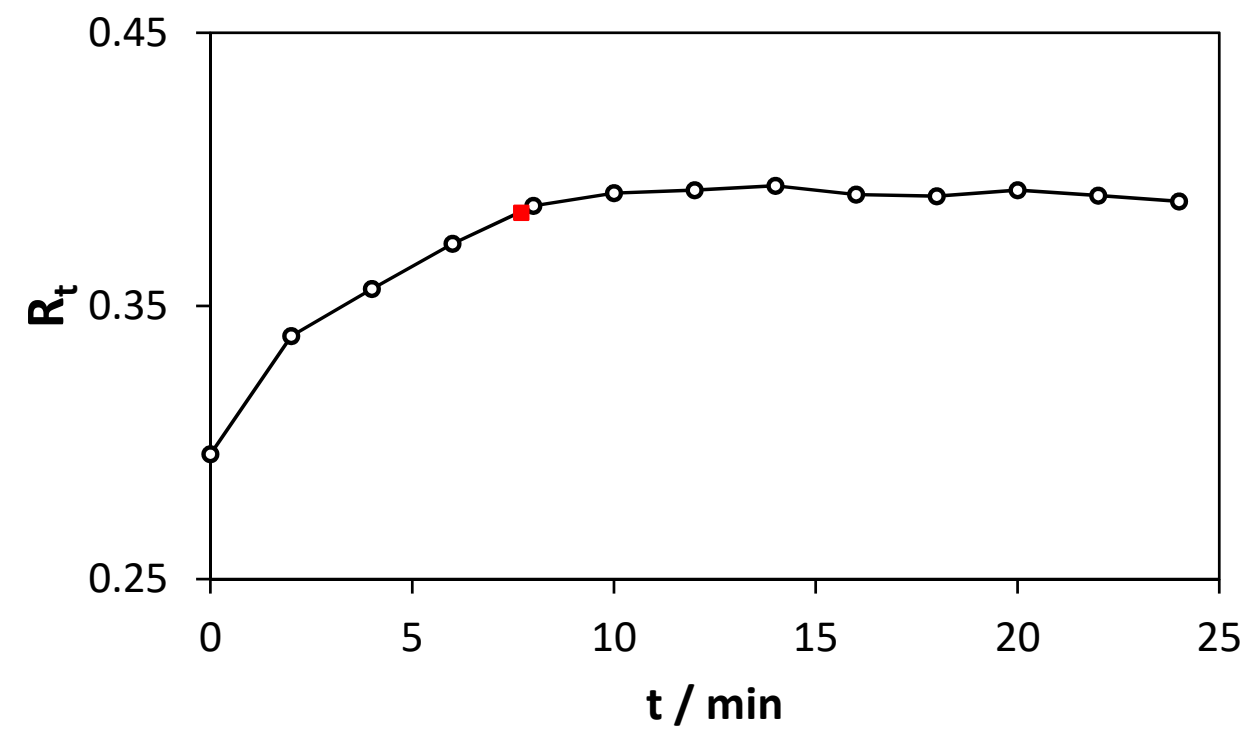

Figure 6: A typical $R_{t}$ vs. $t$ plot used to generate $t$ tb(90) data in Table 3 (red square), in this case for a typical $\mathrm{Rz}$ label tested on a sample of Sheervill $\mathrm{V}$ awning with EverClean photocatalyst coating, and irradiated under standard irradiation conditions of $352 \mathrm{~nm}(\mathrm{FWHM}=40 \mathrm{~nm})$ and $2.0 \mathrm{~mW} \mathrm{~cm}^{-2}$.

The awning photocatalytic material, Sheerfill $V$, is an example of where the $R z$ new label is particularly advantageous over the more traditional paii application methods. Sheerfill $V$ has a smooth, hydrophobic surface, so that when the traditional Rz ink is applied, via the draw-down method, the ink has a tendency to reticulate and so doesn't form a film, rendering the traditional Rz ink test method unusable on this material. In contrast, the screen-printed Rz label has sufficient tack that it adheres to the awning material, thereby allowing the label to provide a measure of its photocatalytic activity. A brief inspection of the results in Table $\mathbf{3}$ show that, for the different materials tested, usually the $t t b(90)$ of the ink is ca. half that of the label, for reasons outlined earlier. 
Table 3: $t t b(90)$ values of the Rz screen-printed label, and reported Rz ink, on different photocatalytic materials surfaces

\begin{tabular}{|c|c|c|c|}
\hline $\begin{array}{l}\text { Surface } \\
\text { Type }\end{array}$ & Product Name & $\begin{array}{l}\text { Label } t t b(90) / \\
\min \end{array}$ & $\begin{array}{l}\text { Ink } t \text { tb(90) I } \\
\min \end{array}$ \\
\hline \multirow{4}{*}{ Glass } & Plain glass & $>60$ & \\
\hline & Sol gel [38] ${ }^{a}$ & $<<0.1$ & $<<0.1$ \\
\hline & Pilkington Activ ${ }^{\mathrm{TM}}[29]$ & 8.8 & $3.8[12]$ \\
\hline & St. Gobain BioClean® [31] & 13.6 & $6.3[47]$ \\
\hline $\begin{array}{l}\text { Architectural } \\
\text { Membrane }\end{array}$ & $\begin{array}{l}\text { St. Gobain Sheerfill V with Everclean }{ }^{\mathrm{TM}} \\
\qquad[32]\end{array}$ & 7.7 & $\begin{array}{l}\text { Not determined } \\
\text { - vide supra }\end{array}$ \\
\hline Paint & Sto Color Climasan [34] & 11.8 & $6.1[12]$ \\
\hline Tile & TOTO Hydrotect ${ }^{\mathrm{TM}}$ coating system [48] & 105 & $63^{b}$ \\
\hline \multicolumn{4}{|c|}{$\begin{array}{l}\text { a: Sol gel films prepared as described in Table 1, with dry thickness ca. 8x lower than a typical sol-gel } \\
\text { film as described in cited literature [39], and yet it still requires }<6 \mathrm{~s} \text { UV irradiation to change the colour } \\
\text { of the Rz label or ink. }\end{array}$} \\
\hline
\end{tabular}

Finally, one of the key features of the Rz label is that it can be used readily in situ and, in particular, it can be used to assess the activity of vertical or tilted samples, such as glass panes, in situ. An illustration of this is given in Figure 7, which shows the colour changes undergone by an Rz label stuck to a vertical sheet of self-cleaning glass upon its UV irradiation. 


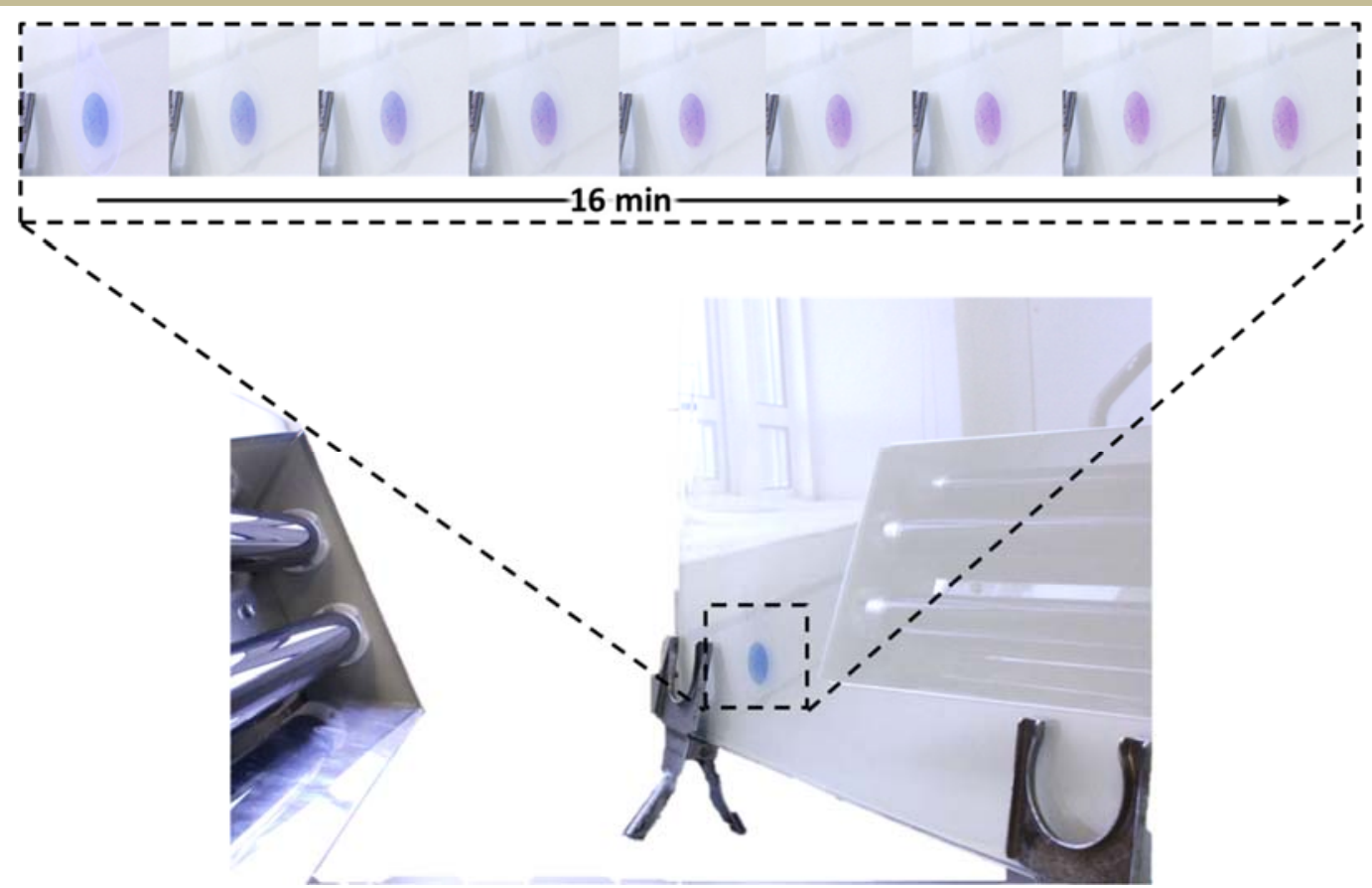

Figure 7: The in-situ application of the Rz label on a vertically-oriented sample of self-cleaning glass. Also in the picture is the UV irradiation source (two $15 \mathrm{~W}$ BLB lamps with $\lambda_{\mathrm{em}}$ at $365 \mathrm{~nm}$, and with a UV irradiance of $2.0 \mathrm{~mW}$ $\mathrm{cm}^{-2}$ ). The insert plot shows the colour changes undergone by the label as a function of irradiation time. RGB data analysis of these yields a $t \mathrm{tb}(90)$ value of $8.5 \mathrm{~min}$.

\subsection{Conclusions}

A novel delivery system for the established resazurin photocatalyst activity indicator ink (paii) system is reported, comprising a central Rz ink film, which uses HPC as the encapsulating polymer, and a PSA ring which helps secures the label in place. The label is about 2 times slower than the more commonly used Rz photocatalytic activity indicator ink. However, it is very stable, easily stored, readily utilised and applicable to vertical as well as horizontal surfaces, making it well suited for use in the field, i.e. for the in situ assessment of the activity of photocatalytic active films, i.e. quantitative analysis, or the identification of a photocatalytic surface, qualitative analysis. 


\subsection{References}

[1] Markets for Self-Cleaning Coating and Surfaces: 2015 to $2022 \mid$ n-tech Research, (n.d.). http://ntechresearch.com/market_reports/markets-for-self-cleaning-coating-and-surfaces-2015-to2022 (accessed October 30, 2017).

[2] C. Han, J. Andersen, S.C. Pillai, R. Fagan, P. Falaras, J.A. Byrne, P.S.M. Dunlop, H. Choi, W. Jiang, K. O'Shea, D.D. Dionysiou, Chapter Green Nanotechnology: Development of Nanomaterials for Environmental and Energy Applications, in: Sustain. Nanotechnol. Environ. Adv. Achiev., American Chemical Society, 2013: pp. 201-229. doi:10.1021/bk-2013-1124.ch012.

[3] D. Synnott, N. Nolan, D. Ryan, J. Colreavy, S.C. Pillai, 14 - Self-cleaning tiles and glasses for eco-efficient buildings, in: Nanotechnol. Eco-Effic. Constr., Woodhead Publishing, 2013: pp. 327-342. doi:10.1533/9780857098832.3.327.

[4] International Standards Organisation, ISO 10678: 2010, Fine ceramics, advanced technical ceramics - determination of photocatalytic activity of surfaces in an aqueous medium by degradation of methylene blue', ISO, Geneva, 2010.

[5] A. Mills, C. Hill, P.K.J. Robertson, Overview of the current ISO tests for photocatalytic materials, J. Photochem. Photobiol. Chem. 237 (2012) 7-23. doi:10.1016/j.jphotochem.2012.02.024.

[6] A. Mills, N. Wells, Reductive photocatalysis and smart inks, Chem. Soc. Rev. 44 (2015) 2849-2864. doi:10.1039/C4CS00279B.

[7] Photocatalyst activity indicator ink, (2016). https://en.wikipedia.org/w/index.php?title=Photocatalyst_activity_indicator_ink\&oldid=734282076 (accessed November 13, 2017).

[8] A. Mills, J. Wang, S.-K. Lee, M. Simonsen, An intelligence ink for photocatalytic films, Chem. Commun. 0 (2005) 2721-2723. doi:10.1039/B501131K.

[9] Photocatalyst activity indicator (PAII) Pens - Multipack - The Intelligent Pen and Ink Company - Photocatalytic Testing Pens \& Equipment, Intell. Pen Ink Co. (n.d.). http://www.inkintelligent.com/product/photocatalyst-activity-indicator-piia-pens-multipack/ (accessed November 21, 2017).

[10] A. Mills, J. Wang, M. McGrady, Method of Rapid Assessment of Photocatalytic Activities of Self-Cleaning Films, J. Phys. Chem. B. 110 (2006) 18324-18331. doi:10.1021/jp063577x.

[11] A. Kafizas, A. Mills, I.P. Parkin, A comprehensive aerosol spray method for the rapid photocatalytic grid area analysis of semiconductor photocatalyst thin films, Anal. Chim. Acta. 663 (2010) 69-76. doi:10.1016/j.aca.2010.01.022.

[12] A. Mills, J. Hepburn, D. Hazafy, C. O’Rourke, N. Wells, J. Krysa, M. Baudys, M. Zlamal, H. Bartkova, C.E. Hill, K.R. Winn, M.E. Simonsen, E.G. Søgaard, S. Banerjee, R. Fagan, S.C. Pillai, Photocatalytic activity indicator inks for probing a wide range of surfaces, J. Photochem. Photobiol. Chem. 290 (2014) 63-71. doi:10.1016/j.jphotochem.2014.06.007. 
[13] S. Kundu, A. Kafizas, G. Hyett, A. Mills, J. A. Darr, I. P. Parkin, An investigation into the effect of thickness of titanium dioxide and gold- silver nanoparticle titanium dioxide composite thin-films on photocatalytic activity and photo-induced oxygen production in a sacrificial system, J. Mater. Chem. 21 (2011) 6854-6863. doi:10.1039/C0JM03492D.

[14] S. In, A. H. Kean, A. Orlov, M. S. Tikhov, R. M. Lambert, A versatile new method for synthesis and deposition of doped, visible light-activated TiO 2 thin films, Energy Environ. Sci. 2 (2009) 12771279. doi:10.1039/B915060A.

[15] C. Tupberg, N. Chandet, K. Wattanavichan, C. Randorn, Catalytic and antibacterial activities of novel colored zinc borophosphate glasses, RSC Adv. 6 (2016) 79602-79611. doi:10.1039/C6RA17232F.

[16] C.W. Dunnill, Z.A. Aikin, J. Pratten, M.W. Wilson, I. Parkin, N-doped Titania Thin Films, Prepared by Atmospheric Pressure Chemical Vapour Deposition: Enhanced Visible Light Photocatalytic Activity and Anti-microbial Effects, ECS Trans. 25 (2009) 65-72. doi:10.1149/1.3207576.

[17] L. Romero, A.-B. Jorge-Sobrido, P.F. McMillian, R. Binions, On titanium dioxide thin films growth from the direct current electric field assisted chemical vapour deposition of titanium (IV) chloride in toluene, Thin Solid Films. 584 (2015) 320-325. doi:10.1016/j.tsf.2015.01.057.

[18] D.S. Bhachu, S. Sathasivam, C.J. Carmalt, I.P. Parkin, PbO-Modified TiO2 Thin Films: A Route to Visible Light Photocatalysts, Langmuir. 30 (2014) 624-630. doi:10.1021/la4038777.

[19] N. Farahani, P.J. Kelly, G. West, C. Hill, V. Vishnyakov, Photocatalytic Activity of Reactively Sputtered Titania Coatings Deposited Using a Full Face Erosion Magnetron, Coatings. 3 (2013) 177193. doi:10.3390/coatings3040177.

[20] E.L. Cuéllar, A. Martínez-de la Cruz, K.H.L. Rodríguez, U.O. Méndez, Preparation of yBi2MoO6 thin films by thermal evaporation deposition and characterization for photocatalytic applications, Catal. Today. 166 (2011) 140-145. doi:10.1016/j.cattod.2010.05.005.

[21] A. Kafizas, D. Adriaens, A. Mills, I. P. Parkin, Simple method for the rapid simultaneous screening of photocatalytic activity over multiple positions of self-cleaning films, Phys. Chem. Chem. Phys. 11 (2009) 8367-8375. doi:10.1039/B905222D.

[22] A.-L. Anderson, R. Binions, The effect of Brijß surfactants in sol-gel processing for the production of TiO2 thin films, Polyhedron. 85 (2015) 83-92. doi:10.1016/j.poly.2014.08.050.

[23] X. Wang, A. Kafizas, X. Li, S.J.A. Moniz, P.J.T. Reardon, J. Tang, I.P. Parkin, J.R. Durrant, Transient Absorption Spectroscopy of Anatase and Rutile: The Impact of Morphology and Phase on Photocatalytic Activity, J. Phys. Chem. C. 119 (2015) 10439-10447. doi:10.1021/acs.jpcc.5b01858.

[24] E. Jimenez-Relinque, M. Castellote, Quantification of hydroxyl radicals on cementitious materials by fluorescence spectrophotometry as a method to assess the photocatalytic activity, Cem. Concr. Res. 74 (2015) 108-115. doi:10.1016/j.cemconres.2015.04.011. 
[25] X. Liu, J. Ma, J. Yang, Visible-light-driven amorphous Fe(III)-substituted hydroxyapatite photocatalyst: Characterization and photocatalytic activity, Mater. Lett. 137 (2014) 256-259. doi:10.1016/j.matlet.2014.09.018.

[26] A.J. Cross, The synthesis, characterisation and functional testing of metal oxide thin films, Doctoral, UCL (University College London), 2014. http://discovery.ucl.ac.uk/1450011/ (accessed November 13, 2017).

[27] N. Williams Portal, P. Rogers, N. Silva, K. Malaga, Photocatalytic activation of textile reinforced concrete facade panels, $\mathrm{CBI}$ Swedish Cement and Concrete Research Institute $A B$, Stockholm, n.d. http://www.h-houseproject.eu/images/04_Documents/02_Publications/WSED_2016_Photocatalytic_activation.pdf (accessed November 13, 2017).

[28] A. Mills, N. Wells, J. MacKenzie, G. MacDonald, Kinetics of reduction of a resazurin-based photocatalytic activity ink, Catal. Today. 281 (2017) 14-20. doi:10.1016/j.cattod.2016.05.045.

[29] How to Buy Activ Glass | Pilkington Self-Cleaning Glass, (n.d.). http://www.pilkington.com/europe/UK\%2Band\%2Bireland/english/products/bp/bybenefit/selfcleaning/a ctiv/find-a-supplier/how-to-buy/default.htm (accessed November 21, 2017).

[30] T.M. Letcher, J.L. Scott, Materials for a Sustainable Future, Royal Society of Chemistry, 2012.

[31] Self Cleaning Glass- Bioclean | Glassolutions, (n.d.). http://glassolutions.co.uk/engb/products/bioclean-self-cleaning-glass (accessed November 21, 2017).

[32] SHEERFILL | SHEERFILL, (n.d.). http://www.sheerfill.com/product-solutions/sheerfill (accessed October 30, 2017).

[33] K.M. Sahlin, J.R. Greno, M.P. Cushman, R.C. Hobbs, J.M. McMartin, Composite article for $\begin{array}{lllll}\text { use as self-cleaning material, US20140066289 } & \text { A1, } & 2014 .\end{array}$ http://www.google.com/patents/US20140066289 (accessed November 2, 2017).

[34] StoColor Climasan fresh air paint, Sto South East Asia. (n.d.). /en/company/innovations/stoclimasan-color/sto-climasan-color-.html (accessed October 30, 2017).

[35] P. Grochal, W. Duttlinger, M. Troll, J. Ermuth, Coating composition, WO2005118726 A1, 2005. http://www.google.com/patents/WO2005118726A1 (accessed November 2, 2017).

[36] AGROB BUCHTAL - Healthy room climate, (n.d.). http://www.agrobbuchtal.de/en/ht/architekten/gesundes-raumklima.html?pe_id=876 (accessed November 21, 2017).

[37] H. Kobayashi, Y. Saeki, S. Tanaka, Y. Nakashima, Y. Mayumi, Method and apparatus for $\begin{array}{lllll}\text { producing a photocatalytic material, US6368668 } & \text { B1, }\end{array}$ http://www.google.com/patents/US6368668 (accessed November 2, 2017).

[38] A. Mills, N. Elliott, G. Hill, D. Fallis, J. R. Durrant, R. L. Willis, Preparation and characterisation of novel thick sol-gel titania film photocatalysts, Photochem. Photobiol. Sci. 2 (2003) 591-596. doi:10.1039/B212865A. 
[39] A. Mills, G. Hill, M. Crow, S. Hodgen, Thick titania films for semiconductor photocatalysis, J. Appl. Electrochem. 35 (2005) 641-653. doi:10.1007/s10800-005-1628-5.

[40] Selecting Proper Mesh Count in Screen Printing, (n.d.). https://www.screenprintingsupply.com/Selecting-Proper-Mesh-Count-in-Screen-Printing_b_5.html (accessed November 13, 2017).

[41] J. Schindelin, I. Arganda-Carreras, E. Frise, V. Kaynig, M. Longair, T. Pietzsch, S. Preibisch, C. Rueden, S. Saalfeld, B. Schmid, J.-Y. Tinevez, D.J. White, V. Hartenstein, K. Eliceiri, P. Tomancak, A. Cardona, Fiji: an open-source platform for biological-image analysis, Nat. Methods. 9 (2012) 676-682. doi:10.1038/nmeth.2019.

[42] A. Mills, N. Wells, C. O'Rourke, Correlation between $\triangle A$ Abs, $\triangle R G B$ (red) and stearic acid destruction rates using commercial self-cleaning glass as the photocatalyst, Catal. Today. 230 (2014) 245-249. doi:10.1016/j.cattod.2013.11.023.

[43] A. Mills, N. Wells, Indoor and outdoor monitoring of photocatalytic activity using a mobile phone app. and a photocatalytic activity indicator ink (paii), J. Photochem. Photobiol. Chem. 298 (2015) 64-67. doi:10.1016/j.jphotochem.2014.10.019.

[44] P. Chin, D.F. Ollis, Decolorization of organic dyes on Pilkington Activ ${ }^{\mathrm{TM}}$ photocatalytic glass, Catal. Today. 123 (2007) 177-188.

[45] A. Mills, A. Lepre, N. Elliott, S. Bhopal, I.P. Parkin, S.A. O'neill, Characterisation of the photocatalyst Pilkington Activ $^{\mathrm{TM}}$ : a reference film photocatalyst?, J. Photochem. Photobiol. Chem. 160 (2003) 213-224.

[46] A. Mills, J. Hepburn, D. Hazafy, C. O'Rourke, J. Krysa, M. Baudys, M. Zlamal, H. Bartkova, C.E. Hill, K.R. Winn, M.E. Simonsen, E.G. Søgaard, S.C. Pillai, N.S. Leyland, R. Fagan, F. Neumann, C. Lampe, T. Graumann, A simple, inexpensive method for the rapid testing of the photocatalytic activity of self-cleaning surfaces, J. Photochem. Photobiol. Chem. 272 (2013) 18-20. doi:10.1016/j.jphotochem.2013.08.004.

[47] A. Mills, C. O'Rourke, N. Wells, A smart ink for the assessment of low activity photocatalytic surfaces, The Analyst. 139 (2014) 5409-5414. doi:10.1039/c4an01375a.

[48] Hydrotect $\quad$ TOTO, $\quad$ (n.d.). http://gb.toto.com/products/product-singleview/Product/show/Hydrotect/ (accessed November 21, 2017). 